\title{
Survey of the practice of spinal cord stimulators and intrathecal analgesic delivery implants for management of pain in Canada
}

\author{
Philip WH Peng MBBS FRCPC ${ }^{1}$, Ingrid Fedoroff PhD R Psych², \\ Line Jacques MD MSC FRCSC DABNS ${ }^{3}$, Krishna Kumar MBBS MS FRCSC ${ }^{4}$
}

\begin{abstract}
PWH Peng, I Fedoroff, L Jacques, K Kumar. Survey of the practice of spinal cord stimulators and intrathecal analgesic delivery implants for management of pain in Canada. Pain Res Manage 2007;12(4):281-285.
\end{abstract}

BACKGROUND: In 2006, the Canadian Neuromodulation Society was formed. The present survey characterizes the practice of spinal cord stimulator (SCS) and intrathecal analgesic delivery pump (IADP) implantation for pain management in different centres across Canada.

METHOD: A structured questionnaire was designed to examine the funding source, infrastructure and patient screening process in different centres implanting SCSs and IADPs. Centres that performed more than 10 implants per year were surveyed. The survey was centrebased, ie, each centre received one questionnaire regardless of the number of staff involved in neuromodulation practice.

RESULTS: Fourteen centres were identified and 13 responded. Implantation of SCS and IADP was performed in 12 and 10 centres, respectively. In most centres, failed back surgery syndrome was the most frequent indication for SCS and IADP implantation. For SCS, all centres always performed a trial; the majority used percutaneous electrode $(83 \%)$ before the SCS implantation. Routine psychological screening was performed in $25 \%$ of centres before any SCS trial procedure. For IADP, all centres performed a trial injection or infusion before implantation. Five centres $(50 \%)$ performed psychological screening in almost all patients. Continuous infusion techniques were the most popular (50\%) used for the trial.

CONCLUSION: The present survey provides a 'snapshot' of the practice of SCS and IADP implantation in Canada. A review of SCS and IADP trials indicated that Canadian practices are mostly, but not always, consistent with those elsewhere.

Key Words: Intrathecal pumps; Neuromodulation; Pain management; Spinal cord stimulators; Survey

\section{Enquête sur la pose de stimulateurs de moelle épinière et de dispositifs d'administration d'analgésiques par voie intrathécale pour le soulagement de la douleur au Canada}

CONTEXTE : La Canadian Neuromodulation Society a été fondée en 2006. La présente enquête visait à caractériser la pratique de la pose de stimulateurs de moelle épinière (SME) et de dispositifs d'administration d'analgésiques par voie intrathécale pour le soulagement de la douleur, dans différents centres, au Canada.

MÉTHODE : Nous avons élaboré un questionnaire structuré portant sur les sources de financement, l'infrastructure et le processus de sélection des patients dans différents centres de pose de SME et de dispositifs d'administration intrathécale (DAI). L'enquête a été menée dans les centres qui effectuaient plus de 10 poses d'appareils par année. L'étude était de type centrique, c'est-à-dire que chaque centre a reçu un questionnaire, quel que soit le nombre de personnes affectées à la neuromodulation.

RÉSULTATS : Nous avons repéré 14 centres, et 13 d'entre eux ont répondu au questionnaire. La pose de SME et de DAI se pratiquait dans 12 centres et dans 10 centres respectivement. Dans la plupart des centres, la principale indication de la pose des appareils était l'échec d'une intervention chirurgicale au dos. En ce qui concerne les SME, on procédait toujours, dans tous les centres, à un essai, qui consistait habituellement en l'application d'une électrode percutanée ( $83 \%$ ) avant la pose de l'appareil. Cependant, le dépistage psychologique était effectué de façon systématique, avant les essais, dans $25 \%$ des centres seulement. Quant aux DAI, on procédait, dans tous les centres, à un essai par injection ou par perfusion avant la pose de l'appareil. Le dépistage psychologique était effectué chez presque tous les patients dans cinq centres (50\%). On utilisait le plus souvent ( $50 \%$ ) les techniques de perfusion continue dans les essais.

CONCLUSION : La présente enquête fournit une image éclair de la pratique de la pose de SME et de DAI au Canada. Un examen des essais de SME et de DAI a révélé que la pratique de la pose de ces appareils au Canada était la plupart du temps, mais pas toujours, conforme à celle qui se fait ailleurs.

The present survey was designed to characterize the practice of SCS and intrathecal analgesic delivery pump (IADP) implantation for pain management in different centres across Canada.

\section{METHOD}

A structured questionnaire was designed to obtain information for the purposes of Canadian Neuromodulation Society members and others. The questionnaire was piloted among executive members of the society. In Canada, Medtronic Canada predominates the market share for SCSs and intrathecal mplantation of spinal cord stimulators (SCSs) and intrathemanagement (1). Because of the expertise required and the cost of the implants, the procedures are usually limited to a small number of centres in Canada. To date, no systematic information about the practice patterns of neuromodulation across Canada has been available.

In 2006, the Canadian Neuromodulation Society was formed. The members include health care professionals involved or interested in the practice or research of neuromodulation.
${ }^{1}$ Department of Anesthesiology and Pain Management, Toronto Western Division, University Health Network, University of Toronto, Toronto,

Ontario; ${ }^{2}$ Chronic Pain Centre, St Paul's Hospital, University of British Columbia, Vancouver, British Columbia; ${ }^{3}$ Montreal Neurological

Hospital, McGill University Health Centre, McGill University, Montreal, Quebec; ${ }^{4}$ Department of Neurosurgery, Regina General Hospital,

University of Saskatchewan, Regina, Saskatchewan

Correspondence: Dr Philip WH Peng, McL 2-405, Toronto Western Hospital, 399 Bathurst Street, Toronto, Ontario M5T 2 S8.

Telephone 416-603-5118, fax 416-603-6494, e-mail philip.peng@uhn.on.ca 


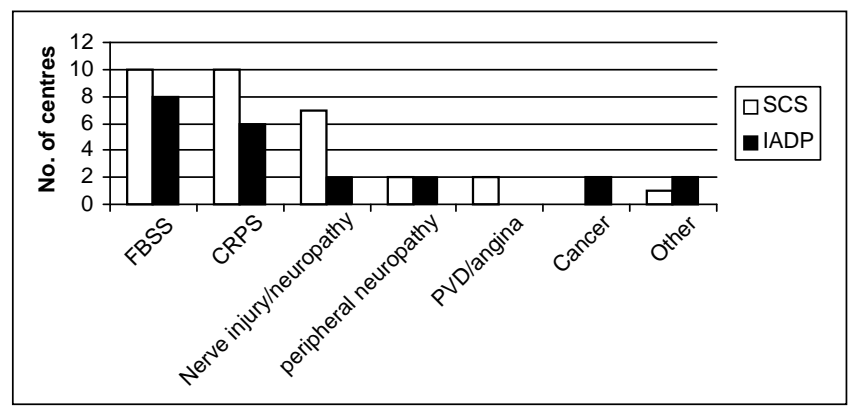

Figure 1) Indications for spinal cord stimulators (SCS) and intrathecal analgesic delivery pumps (IADP). CRPS Complex regional pain syndrome; FBSS Failed back surgery syndrome; PVD Peripheral vascular disease, including angina

\section{TABLE 1}

Funding source of implants and staff

\begin{tabular}{lcccc}
\hline Funding source & $\begin{array}{c}\text { SCS } \\
\text { implant }\end{array}$ & $\begin{array}{c}\text { IADP } \\
\text { implant }\end{array}$ & Nurse & Psychologists \\
\hline Hospital & 6 & 4 & 10 & 4 \\
Provincial & 4 & 4 & 2 & 3 \\
Third party/WSIB & - & - & - & 5 \\
Provincial, third party/WSIB & 2 & 2 & - & - \\
\hline
\end{tabular}

IADP Intrathecal analgesic delivery pump; SCS Spinal cord stimulator; WSIB Workplace and safety insurance board or equivalent workplace insurance agency in various provinces

pumps. Based on the company information, centres that performed more than 10 implants in the past year were surveyed. The survey was centre-based, ie, each centre received one questionnaire regardless of the number of staff involved in neuromodulation practice. The questionnaires were sent either by mail or given directly to the directors or coordinators of each individual centre during a business meeting conducted in May 2006. If the completed questionnaires were not returned within three weeks, the directors were reminded by mail. Descriptive statistics were used to summarize the survey results.

\section{General information}

\section{RESULTS}

Fourteen centres were identified using the list provided by Medtronic Canada, and were located in all provinces except Prince Edward Island, and Newfoundland and Labrador. Thirteen centres responded (93\%), with implantation procedures of SCS and IADP performed in 12 and 10 centres, respectively.

In most centres, failed back surgery syndrome (FBSS, chronic lumbar and/or lower extremity pain after lumbar spine surgery) was identified as the top indication for both SCS and IADP implantation. The frequency of indications for both types of implants are shown in Figure 1.

Both provincial and hospital funding were the major sources of funding for SCS and IADP implants (Table 1). The most common referral sources were pain specialists and neurosurgeons $(82 \%)$, followed by family physicians $(62 \%)$ and orthopedic surgeons (58\%). Because the implantation procedures were most often performed in major municipalities, a majority of the patients were out-of-city patients (Figure 2). The median number of staff in each neuromodulation centre

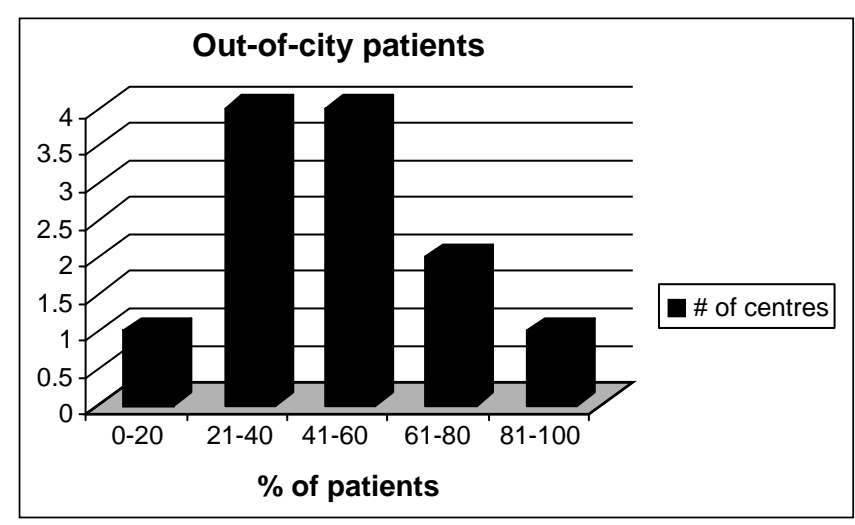

Figure 2) Out-of-city referrals in various centres

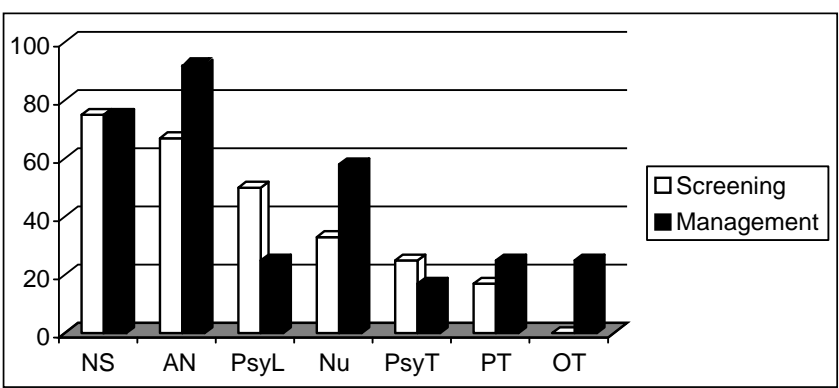

Figure 3) Staff involvement in screening and management spinal cord stimulators. AN Anesthesiologist; NS Neurosurgeon; Nu Nurse; OT Occupation therapist; PsyL Psychologist; PsyT Psychiatrist; PT Physiotherapist

was two (range one to five). Approximately one-half of the centres (seven of 13) had a database for patient information that included patient demographics, surgical data, pain measurements, functional activity and quality of life information.

\section{SCS implantation}

Most of the centres provided a multidisciplinary team for the management of SCS patients. Both neurosurgeons and anesthesiologists were frequently involved in the team (Figure 3). Routine psychological screening was performed in $25 \%$ of centres before any SCS trial procedure. Either psychologists or neuropsychologists performed the screening, with the exception of one centre, in which a psychiatrist performed the screening.

With the exception of management of patients with refractory angina, all centres chose a two-stage procedure - a trial before the implantation. When asked about the common scenario for the trial, $83 \%$ of the centres used a percutaneous lead for trial (Verify lead 50\%, Quad lead 33\%, Medtronic Canada). Only $17 \%$ of the centres considered using a surgical electrode (Resume lead, Medtronic Canada) for the trial. In $66 \%$ of the centres, the trials were performed by neurosurgeons, compared with $25 \%$ of trials performed by anesthesiologists. However, implantation procedures were performed predominantly by surgeons (neurosurgeons [75\%], orthopedic surgeons [8\%], or combined surgeon and anesthesiologist [8\%]). The trial procedures were performed mainly on an outpatient basis $(75 \%)$ and lasted for more than six days in most of the centres. When asked about the biggest challenges in 
delivering neuromodulation therapy at their respective centres, most centres considered the following two issues: funding (for implants, nursing or psychologists) and the time and energy resources spent in managing the complex patients.

\section{IADP implantation}

There were 10 centres in this survey performing intrathecal pump implantation. In most of the centres, the trial procedures were performed by anesthesiologists alone (seven centres) or with a neurosurgeon (one centre). Only one centre had the trial performed by a neurologist. In contrast, implantations were commonly performed by neurosurgeons (seven centres), followed by anesthesiologists (three centres). Five centres incorporated psychological screening for almost all of their patients. All centres routinely performed a trial before the pump implantation. Most centres chose a continuous infusion technique as the trial method (Table 2).

The most popular medication in the intrathecal pump was opioids alone (nine centres). Morphine was the most popular choice in six centres, and three centres preferred hydromorphone. Seven centres also combined opioids with an adjuvant; bupivacaine and clonidine were commonly chosen. Two complications of IADPs, meningitis and severe hormonal disturbance, were reported in five and four centres, respectively. Meningitis occurred mostly in the trial stage. Three centres reported intrathecal granuloma (total four patients) in their patient population.

\section{DISCUSSION}

Neuromodulation is a field of science, medicine and bioengineering that encompasses both implantable and nonimplantable technologies (electrical and chemical) that improve quality of life (2). Neuromodulation techniques are now most commonly used for the treatment of pain, although they are also used for the treatment of movement, psychiatric, genitourinary and gastrointestinal disorders. The present survey was designed to provide a 'snapshot' of the practice of SCS and IADP implantation for the management of pain in Canada. This information provides the newly formed Canadian Neuromodulation Society and others interested with important information about the activities of various centres across Canada.

SCSs have been used for four decades for the treatment of refractory pain, especially FBSS and complex regional pain syndromes (CRPS) (3). The implantable system includes an electrode lead introduced into the epidural space either by percutaneous approach or through laminotomy. The electrode lead is connected to either a fully implanted pulse generator that uses a built-in battery, or an implanted device that is coupled to an external power supply using radiofrequency coupling technology. The latter technology is now rarely used in Canada. Before implantation of the device, physicians typically perform a trial in which a temporary epidural electrode is inserted either percutaneously or surgically. The extension of this electrode is connected to an external programming device. One centre does not routinely perform trials on patients with refractory angina, because it is one of the centres in North America experienced in implanting SCS in refractory angina patients. The rationale for not performing a trial is that they have a very high success rate in trials for this patient population. The one-stage procedure minimizes the stress of a two-stage procedure in critically ill patients.
TABLE 2

Various trial techniques for intrathecal analgesic delivery pumps

\begin{tabular}{lccc}
\hline & Single bolus & Multiple bolus & Continuous infusion \\
\hline Epidural & - & - & 2 \\
Intrathecal & 2 & 4 & 5 \\
\hline
\end{tabular}

A recent consensus document published by the British Pain Society (4) recommended the following as good indications (likely to respond) for SCS implantation: neuropathic pain in the leg or arm following lumbar or cervical spine surgery (FBSS), CRPS, neuropathic pain secondary to peripheral nerve damage, pain associated with peripheral vascular disease, refractory angina and brachial plexopathy. An early review published in 1995 (5) examining the effectiveness of SCS implantation in patients with FBSS reported at least 50\% pain relief in $50 \%$ to $60 \%$ of patients. However, the literature consisted entirely of case series, mostly retrospective.

To date, there are seven randomized controlled trials published on the use of SCSs for pain management (FBSS, one trial; CRPS, one trial; angina, three trials; peripheral vascular disease, two trials). In one study, CRPS patients with severe pain and disability were randomly assigned to receive either SCS implantation and physiotherapy (SCS+PT) or physiotherapy alone (PT). In an intention-to-treat analysis, the pain relief was significantly better in the SCS+PT groups at six months, one and two years (6-8). The average decrease in pain intensity ranged from 2.1 to 3.6 (out of 10 ) throughout the study period in the SCS+PT group, while the average pain intensity was worse or the same in the PT group. The health-related quality of life was significantly better in the SCS+PT group at one and two years. In another study (9), FBSS patients selected for reoperation were randomly assigned to either SCS implantation or reoperation. If the results of the randomly assigned treatment were unsatisfactory, patients were able to cross over to the alternative. Successful treatment was defined by pain relief (50\% or greater) and self-reported patient satisfaction. All patients were followed up for two years. Successful treatment was more prevalent in the SCS group (47\% versus $16 \%$ ), including lower opioid analgesic consumption. Patients initially randomly assigned to SCS were significantly less likely to cross over to the alternative than those who were randomly assigned for reoperation (five of 24 versus 14 of $26, \mathrm{P}<0.02$ ). Other measures of activities of daily life and work status, however, did not differ significantly.

Mannheimer et al (10) randomly assigned 104 angina patients who were accepted for coronary artery bypass graft (CABG) to receive either CABG surgery or SCS implantation. Results were analyzed on an intention-to-treat basis. The number of angina attacks and nitrate consumption was significantly reduced in both groups and there were no significant intergroup differences. However, the CABG group was found to have a higher mortality rate. Another two randomized control trials on angina used a similar design by delaying SCS treatment in the control groups $(11,12)$. One study randomly assigned the angina patients to have the SCS implanted either at the beginning or two months after the study began. The other study implanted SCS at the beginning of the study period, but randomly assigned angina patients to either using the stimulation right away or delaying the use of stimulation by six weeks. In both studies, SCS implantation resulted in a significant 
decrease in the number of angina attacks and use of nitrates, although the follow-up periods were short (six weeks and two months). Two randomized, controlled trials on SCS implantation and peripheral vascular disease studied patients with critical limb ischemia. One study (13) randomly assigned 51 such patients to receive either oral medication and SCS or oral medication alone. The follow-up duration was 18 months. The investigators found a significant improvement in pain scores in the SCS group compared with the non-SCS group at six, 12 and 18 months. The other study (14) randomly assigned 120 patients to receive either SCS implantation with the best medical treatment, or the best medical treatment alone. The mean follow-up duration was 19 months, and there were no significant differences in pain scores between groups.

Two systematic reviews on SCS implantation $(3,15)$, suggested positive analgesic effects in patients with CRPS, angina and FBSS. However, there was no evidence to indicate that SCSs improve the overall functioning of patients. Both reviews strongly urged the need for good-quality, randomized, controlled, long-term trials. The overall complication rate was $34 \%$. The most common complication was lead problem (such as migration/breakage) requiring revision (23\%). Other less common complications included equipment failure (10\%), stimulator removal $(11 \%$, mostly because of infection, equipment failure or lack of analgesic effect) and superficial infection (4.5\%).

Contrary to the available SCS literature, a recently published systematic review (16) on the effectiveness of IADP for chronic noncancer pain patients found no randomized controlled trials, but included observational studies. Pain and functioning improved in patients who received a permanent IADP. The mean pain intensity (from a scale of zero to 100) decreased from 82 (preimplantation) to 45 and 44 at six and 12 months postimplantation, respectively. However, these data were estimated from a small number of studies and the follow-up rating may be biased by high attrition rates. Success rates (proportion of patients with $50 \%$ or greater pain relief, with patients lost to follow-up considered failures) ranged from 38\% to 56\% at six months and from $30 \%$ to $44 \%$ at longer follow-ups. The most commonly reported adverse effects following IADP implantation were nausea/vomiting (mean rate weighed by sample size [33\%]), urinary retention (24\%) and pruritus (26\%).

In the present survey, FBSS and CRPS were the two most frequent indications for both SCS and IADP implantations. The cost-effectiveness of SCS implantation in these two pain syndromes has been well studied $(17,18)$. In the presence of paucity of resources, it was not surprising that the centres surveyed chose candidates with highly indicated pain syndromes.

The selection of patients is of utmost importance (4). SCS implantation is most effective in managing patients with neuropathic pain. In patients with mixed nociceptive and neuropathic pain (eg, FBSS), only those with predominant radicular pain should be considered. Patients with a past or current history of substance abuse are also typically excluded. Following a thorough assessment by a pain specialist, an assessment of psychosocial issues by an experienced practitioner is important. Chronic pain profoundly affects the lives of sufferers, including their mood, social relationships and quality of life. Considerable evidence exists to support the application of presurgical psychological assessment and the treatment of those biopsychosocial factors that may adversely impact functional outcomes after spine surgery (19). Psychological screening is advocated as an important assessment before physicians consider a trial of neuromodulation technique. In a prospective study (20) examining the prognostic value of psychological screening in SCS implantation, significant associations were observed between the outcome of the therapeutic trial of stimulation and psychological test results. Patients with low 'anxiety' scores on the Derogatis Affects Balance Scale and with high 'organic symptoms' scores on the Wiggins test were significantly more likely to proceed to permanent implants (20). In a survey of all centres performing SCS implantation in the United Kingdom (21), a vast majority of the centres followed guidelines published by the European Federation of IASP Chapters (1). Sixty-one per cent of those centres routinely performed psychological screening. Only 2\% of the centres surveyed did not adopt a psychological screening procedure before the SCS trial. Our results showed that psychological screening took place for the majority of patients in only $40 \%$ and $55 \%$ of the centres implanting SCSs and IADPs, respectively. The reason for these low results is that the Ministry of Health provincial funding does not cover psychological assessment. Thus, physicians cannot screen all patients unless extra sources of coverage for this type of service, such as third party or hospital funding, are available. This is why most respondents in this survey considered the lack of funding for psychologists as one of the major challenges for the delivery of neuromodulation services in their respective centres.

In the present survey, both anesthesiologists and neurosurgeons were the major specialists responsible for the implantation. This is in contrast to practice outside of Canada. In an international survey investigating the practice of IADP implantation in North America, Australia and Europe, $76 \%$ of the respondents were anesthesiologists while only $15 \%$ were neurosurgeons (22). In another survey of neuromodulation centres in the United States, anesthesiologists were responsible for the implantation of SCSs and IADPs in $87 \%$ and $84 \%$ of the centres, while neurosurgeons were responsible in only $62 \%$ of the centres $(23,24)$.

\section{SUMMARY}

The present survey provides only a 'snapshot' of the practice of neuromodulation in Canada. Various health care professionals in the field recently joined forces to form a new society, the Canadian Neuromodulation Society. The mission of this society is to pursue excellence in the application of neuromodulation therapy through education, training, dissemination, support of research and encouragement of best practices. The society will also implement professional development and leadership in health policy on chronic pain management and other neurological disorders. As repeatedly highlighted by recent systematic reviews, randomized controlled trials are needed to further support the effectiveness of SCS and IADP implantation. Another way of examining the real-life long-term effectiveness of these devices is to set up a national database to collect outcome and safety data prospectively. The society has invested manpower and resources to help develop such a database and the data are being collected.

FUNDING: This survey was funded by Medtronic Canada Inc.

CONFLICT OF INTEREST: Drs Kumar, Peng and Jacques have received research grants from Medtronic Canada Inc. 


\section{REFERENCES}

1. Gybels J, Erdine S, Maevaert J, et al. Neuromodulation of pain. A consensus statement prepared in Brussels 16-18 January 1998 by the following task force of the European Federation of IASP Chapters (EFIC). Eur J Pain 1998;2:203-9.

2. Krames ES. Neuromodulatory devices are part of our "Tools of the Trade”. Pain Med 2006;7:S3-5 (Editorial).

3. Turner JA, Loeser JD, Deyo RA, Sanders SB. Spinal cord stimulation for patients with failed back surgery syndrome or complex regional pain syndrome: a systematic review of effectiveness and complications. Pain 2004;108:137-47.

4. Spinal cord stimulation for the management of pain: Recommendations for the best clinical practice. British Pain Society. <www.britishpainsociety.org/SCS_2005.pdf> (Version current at October 3, 2006).

5. Turner JA, Loeser JD, Bell KG. Spinal cord stimulation for chronic low back pain: A systematic literature synthesis. Neurosurgery 1995;37:1088-96.

6. Kemler MA, Barendse GA, van Kleef M, et al. Spinal cord stimulation in patients with chronic reflex sympathetic dystrophy. N Engl J Med 2000;343:618-24.

7. Kemler MA, Furnée CA. Economic evaluation of spinal cord stimulation for chronic reflex sympathetic dystrophy. Neurology 2002;59:1203-9.

8. Kemler MA, De Vet HCW, Barendse GAM, Van Den Wildenberg FAJM, Van Kleef M. The effect of spinal cord stimulation in patients with chronic reflex sympathetic dystrophy: Two years' follow-up of the randomized controlled trial. Ann Neurol 2004;55:13-18.

9. North RB, Kidd DH, Farrokhi F, Piantadosi SA. Spinal cord stimulation versus repeated lumbosacral spine surgery for chronic pain: a randomized, controlled trial. Neurosurgery 2005;56:98-107.

10. Mannheimer C, Eliasson T, Augustinsson L, et al. Electrical stimulation versus coronary artery bypass surgery in severe angina pectoris: The ESBY study. Circulation 1998;97:1157-63.

11. de Jongste MJ, Hautvast RW, Hillege HL, Lie KI. Efficacy of spinal cord stimulation as adjuvant therapy for intractable angina pectoris: A prospective, randomized clinical study. Working Group on Neuroradiology. J Am Coll Cardiol 1994;23:1592-7.

12. Hautvast RW, DeJongste MJ, Staal MJ, van Gilst WH, Lie KI. Spinal cord stimulation in chronic intractable angina pectoris: A randomized, controlled efficacy study. Am Heart J 1998;136:1114-20.
13. Jivegard LEH, Augustinsson LE, Holm J, Risberg B, Ortenwall P. Effects of spinal cord stimulation (SCS) in patients with inoperable severe lower limb ischaemia: A prospective randomised controlled study. Eur J Vasc Endovasc Surg 1995;9:421-5.

14. Klomp HM, Spincemaille GH, Steyerberg EW, Habbema JD, van Urk H. Spinal cord stimulation in critical limb ischaemia: A randomised trial. ESES Study Group. Lancet 1999;353:1040-4.

15. Cameron T. Safety and efficacy of spinal cord stimulation for the treatment of chronic pain: A 20-year literature review. J Neurosurg 2004;100(Suppl Spine 3):254-67.

16. Turner JA, Sears JM, Loeser JD. Programmable intrathecal opioid delivery system for chronic non-cancer pain: A systematic review of effectiveness and complications. Clin J Pain 2007;23:180-95.

17. Kumar K, Malik S, Deneria D. Treatment of chronic pain with spinal cord stimulation versus alternative therapies: Costeffectiveness analysis. Neurosurgery 2002;51:106-16.

18. Taylor RS, Taylor RJ, Van Buyten JP, Buchser E, North R, Bayliss S. The cost effectiveness of spinal cord stimulation in the treatment of pain: A systematic review of the literature. J Pain Symptom Manage 2004;27:370-8.

19. Van Dorsten B. Psychological considerations in preparing patients for implantation procedures. Pain Med 2006; 7:S47-57.

20. North RB, Kidd DH, Wimberly RL, Edwin D. Prognostic value of psychological testing in patients undergoing spinal cord stimulation: A prospective study. Neurosurgery 1996;39:301-11.

21. Ackroyd R, Bush DJ, Graves J, McVey J, Horton S. Survey of assessment criteria prior to implantation of spinal cord stimulators in United Kingdom pain management centers. Eur J Pain 2005;9:57-60.

22. Hassenbusch SJ, Portenoy RK. Current practices in intraspinal therapy - A survey of clinical trends and decision making. J Pain Symptom Manage 2000;20:S4-S11.

23. Fanciullo GJ, Rose RJ, Lunt PG, Whalen PK, Ross E. The state of implantable pain therapies in the United States: A nationwide survey of academic teaching programs. Anesth Analg 1999;88:1311-6.

24. Ahmed SU, Martin NM, Chang Y. Patient selection and trial methods for intraspinal drug delivery for chronic pain: A national survey. Neuromodulation 2005;8:112-20. 


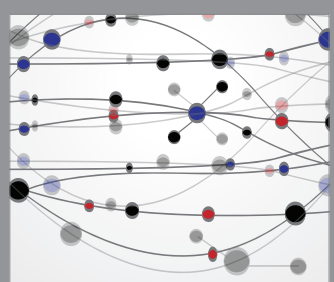

The Scientific World Journal
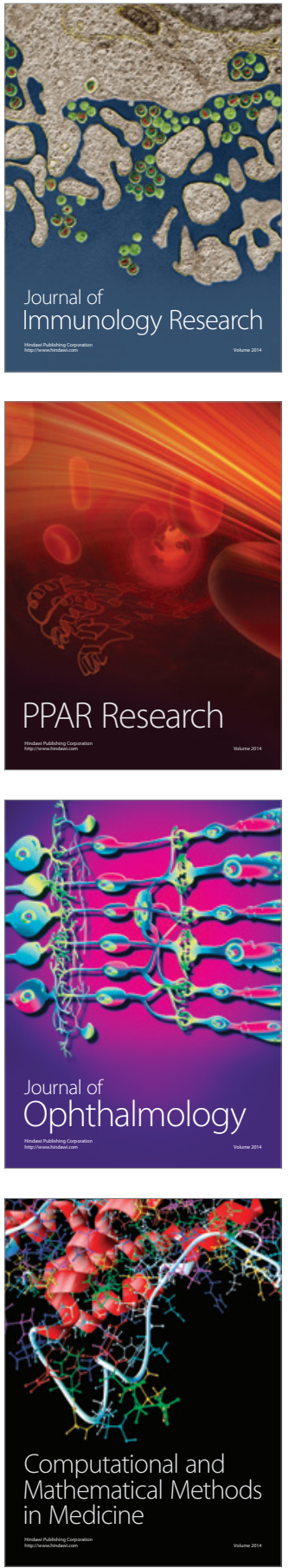

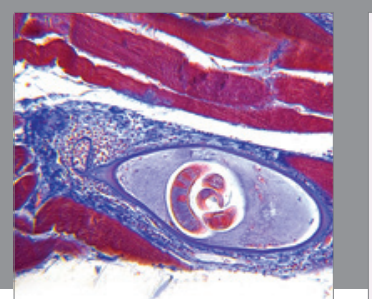

Gastroenterology Research and Practice

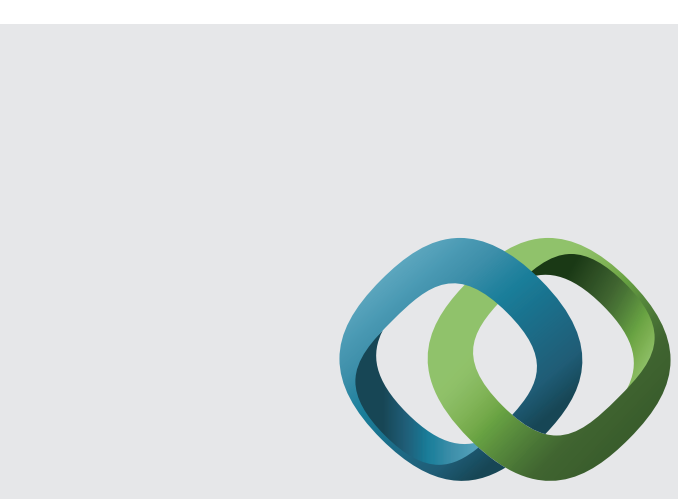

\section{Hindawi}

Submit your manuscripts at

http://www.hindawi.com
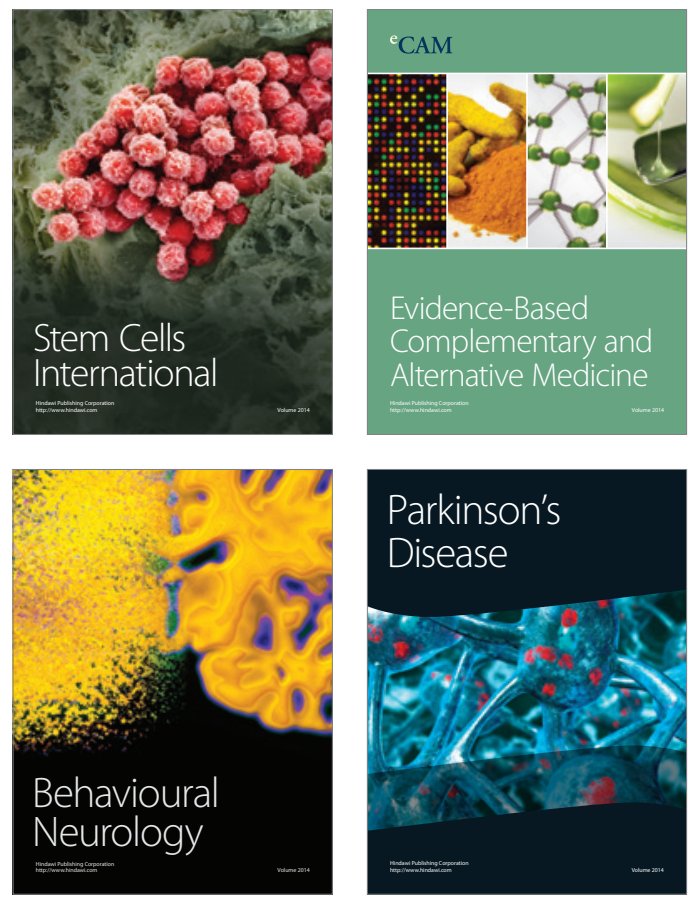
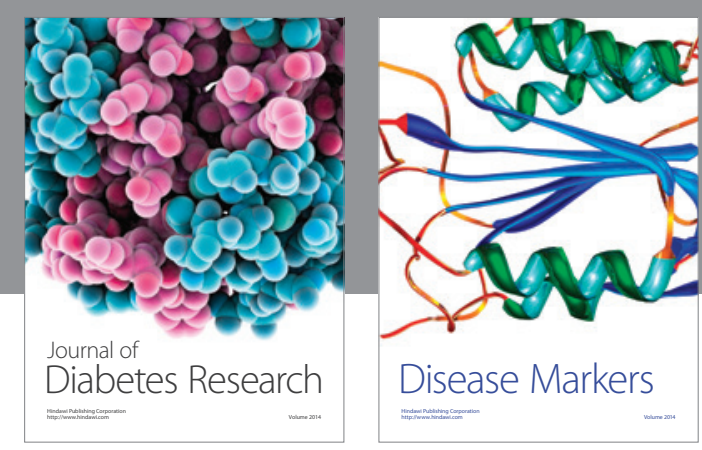

Disease Markers
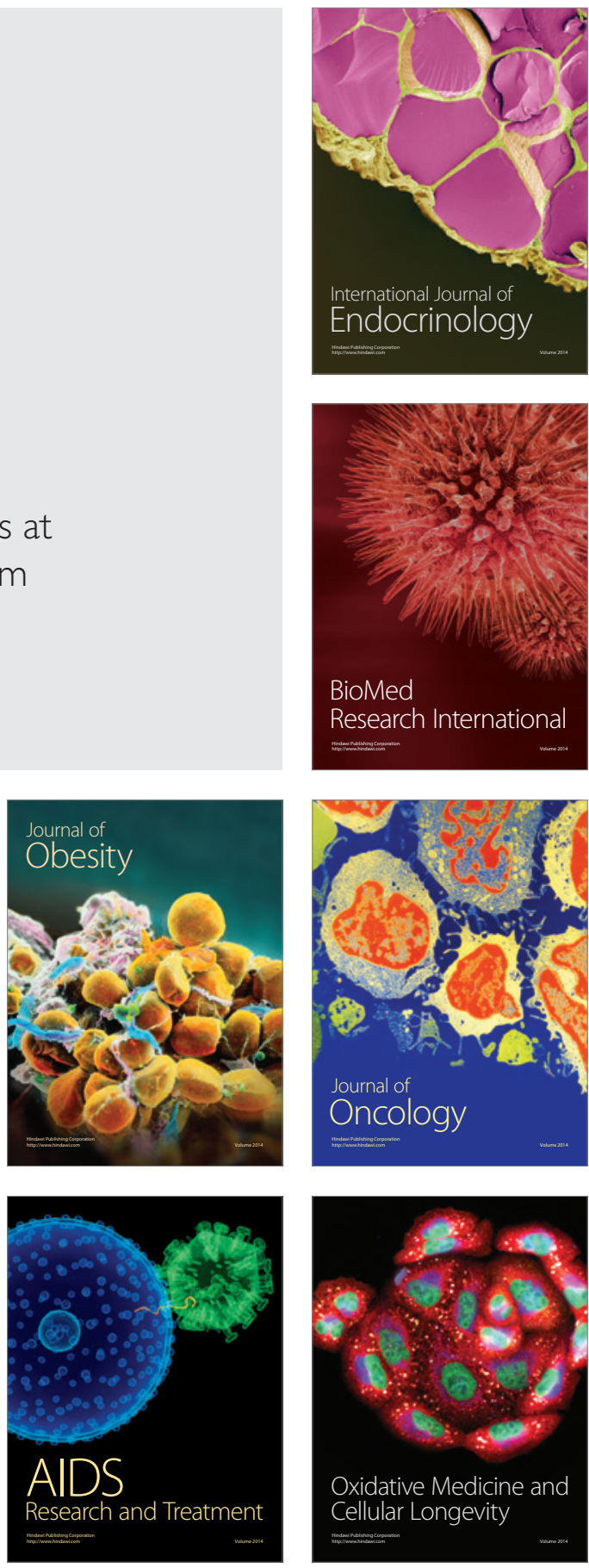